\section{Endosonographic Findings in Pseudomyxoma Peritonei}

A 73-year-old man presented with severe vomiting and weight loss. Upper endoscopy revealed evidence of gastric luminal compression. Endoscopic ultrasound (EUS) using an Olympus GF-UM 20 echo endoscope revealed a diffuse, inhomogeneous lesion with mixed echogenicity, encircling the stomach and compressing it. Multiple, small, circular, hypoechoic areas were seen. Septations were also visualized (Figure 1). A computed tomographic scan revealed a mixed-density lesion encircling the abdominal viscera (Figure 2). Surgical biopsy revealed sheets of mucin with scattered cells compatible with pseudomyxoma peritonei, due to a mucinous adenocarcinoma.

Pseudomyxoma peritonei usually disseminates throughout the peritoneal cavity after arising from a mucin-producing primary malignancy (1). A definitive diagnosis is usually made at the time of laparotomy, when this mucinous, jelly-like material is encountered (2). Septations and hypoechoic mucinous nodules appear to be a sonographic sign of this disease (3). No reports of EUS findings in pseudomyxoma peritonei have hitherto been published. The multiple, circular, hypoechoic lesions anterior to the stomach on EUS (Figure 1) appear to represent mucinous nodules with septations around them. These quite characteristic sonographic findings in pseudomyxoma peritonei can suggest this diagnosis during EUS. With the advent of EUS-guided fine-needle aspiration $(4,5)$, tumors like the one reported here, may in future be amenable to histological confirmation without surgery.

\section{S. Bhutani, C. J. Barde}

Veterans' Administration Medical Center, Division of Gastroenterology, Wright State University, Dayton, Ohio, USA

\section{References}

1. Sugarbaker PH, Kern K, Lack E. Malignant pseudomyxoma peritonei of colonic origin: natural history and presentation of a curative approach to treatment. Dis Colon Rectum 1987; 30: $772-9$.

2. Runyon BA. Surgical peritonitis and other diseases of the peritoneum, mesentery, omentum, and diaphragm. In: Sleisenger MH, Fordtran JS, editors. Gastrointestinal disease. 5 th ed. Philadelphia: Saunders, 1993: 2010.

3. Seshul MB, Coulam CM. Pseudomyxoma peritonei: computed tomography and sonography. Am J Roentgenol 1981; 136: 803-6.

4. Giovannini M, Seitz JF, Monges G, Perrier H, Rabbia I. Fineneedle aspiration guided by endoscopic ultrasonography: results in 141 patients. Endoscopy 1995; 27: $171-7$.

5. Bhutani M, Hoffman B, van Velse A, Sanders-Cliette A, Hawes R. Endoscopic ultrasound-guided fine-needle aspiration of malignant pancreatic lesions: accuracy, safety and clinical utility [abstract]. Gastrointest Endosc 1995; 41: 298.

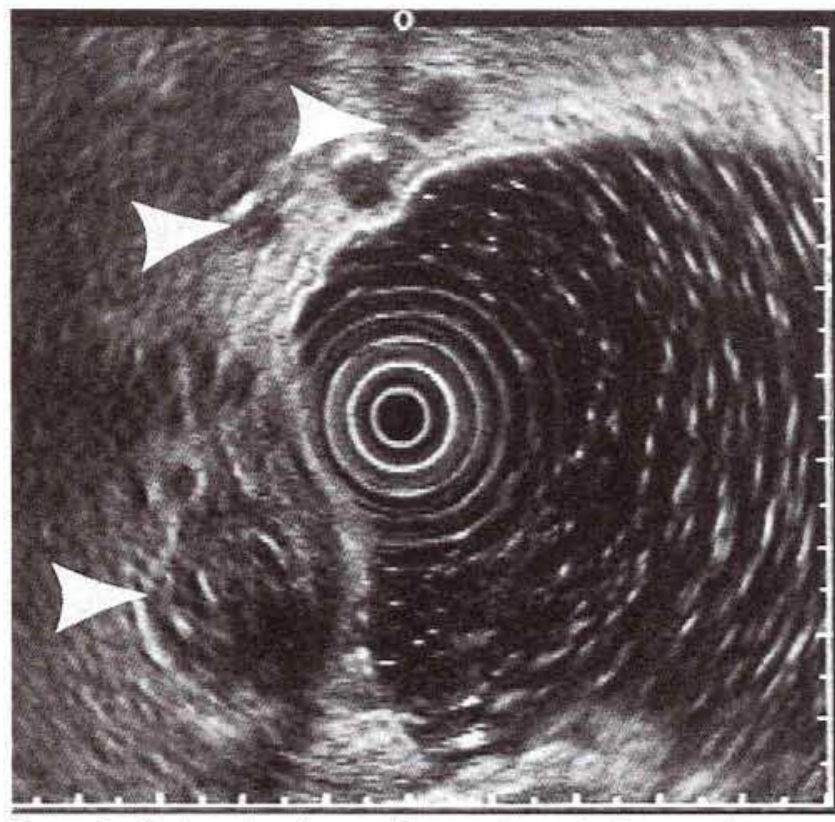

Figure 1: Endoscopic ultrasound image demonstrating pseudomyxoma peritonei around the stomach. Note the hypoechoic cystic structures and septa (arrows).

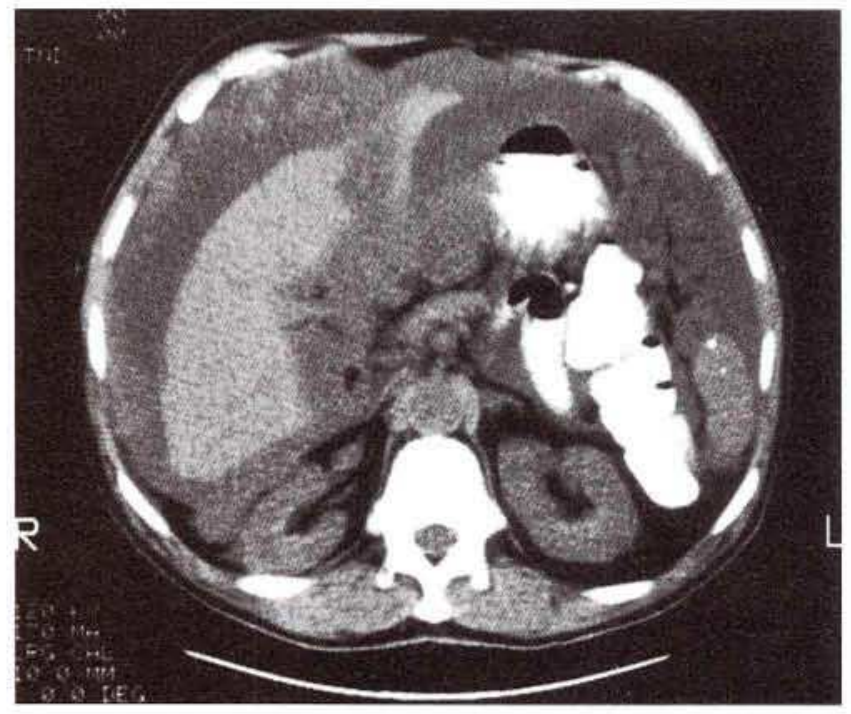

Figure 2: Computed tomographic scan revealing a diffuse mass around the abdominal viscera.

Corresponding Author

M. S. Bhutani, M. D.

Chief of Endoscopy

Medical Service (111)

Veterans' Administration Medical Center

4100 West Third Street

Dayton, $\mathrm{OH} 45426$

USA

Fax: $+1-513-2673934$ 